\title{
BMJ Open Readmissions and mortality in delirious versus non-delirious octogenarian patients after aortic valve therapy: a prospective cohort study
}

\author{
Leslie S P Eide, ${ }^{1,2}$ Anette H Ranhoff, ${ }^{2}$ Bengt Fridlund, ${ }^{3}$ Rune Haaverstad, ${ }^{4}$ \\ Karl Ove Hufthammer, ${ }^{5}$ Karel K J Kuiper, ${ }^{4}$ Jan Erik Nordrehaug, ${ }^{6}$ \\ Tone M Norekvål, ${ }^{4}$ on behalf of the CARDELIR Investigators
}

To cite: Eide LSP, Ranhoff AH, Fridlund B, et al. Readmissions and mortality in delirious versus nondelirious octogenarian patients after aortic valve therapy: a prospective cohort study. BMJ Open 2016;6: e012683. doi:10.1136/ bmjopen-2016-012683

- Prepublication history and additional material is available. To view please visit the journal (http://dx.doi.org/ 10.1136/bmjopen-2016012683).

Received 17 May 2016 Revised 5 August 2016 Accepted 14 September 2016

CrossMark

For numbered affiliations see end of article.

Correspondence to Leslie S P Eide; Ipe@hib.no

\section{ABSTRACT}

Objectives: To determine whether postoperative delirium predicts first-time readmissions and mortality in octogenarian patients within 180 days after aortic valve therapy with surgical aortic valve replacement (SAVR) or transcatheter aortic valve implantation (TAVI), and to determine the most common diagnoses at readmission.

Design: Prospective cohort study of patients undergoing elective SAVR or TAVI.

Setting: Tertiary university hospital that performs all SAVRs and TAVIs in Western Norway.

Participants: Patients $80+$ years scheduled for SAVR or TAVI and willing to participate in the study were eligible.

Those unable to speak Norwegian were excluded. Overall, 143 patients were included, and data from 136 are presented.

Primary and secondary outcome measures: The primary outcome was a composite variable of time from discharge to first all-cause readmission or death.

Secondary outcomes were all-cause first readmission alone and mortality within 180 days after discharge, and the primary diagnosis at discharge from first-time readmission. Delirium was assessed with the confusion assessment method. First-time readmissions, diagnoses and mortality were identified in hospital information registries.

Results: Delirium was identified in $56 \%$ of patients. The effect of delirium on readmissions and mortality was greatest during the first 2 months after discharge (adjusted HR $2.9(95 \% \mathrm{Cl} 1.5$ to 5.7$))$. Of 30 first-time readmissions occurring within 30 days, $24(80 \%)$ were patients who experienced delirium. 1 patient (nondelirium group) died within 30 days after therapy. Delirious patients comprised $35(64 \%)$ of 55 first-time readmissions occurring within 180 days. Circulatory system diseases and injuries were common causes of first-time readmissions within 180 days in delirious patients. 8 patients died 180 days after the procedure; $6(75 \%)$ of them experienced delirium.

Conclusions: Delirium in octogenarians after aortic valve therapy might be a serious risk factor for postoperative morbidity and mortality. Cardiovascular disorders and injuries were associated with first-time readmissions in these patients.
Strengths and limitations of this study

- This is the first study that systematically evaluates delirium for 5 postoperative days, focusing exclusively in octogenarian patients undergoing aortic valve therapy with surgical aortic valve replacement (SAVR) or transcatheter aortic valve implantation (TAVI), and aiming to establish whether delirium predicts first-time readmissions and mortality within 180 days after hospital discharge.

- The high rate of inclusion in this study ensures that the data are representative of octogenarians with severe aortic stenosis referred for SAVR or TAVI and makes our results comparable to other studies that sampled more populated areas.

- Data are limited to a tertiary university hospital.

- This study concentrates in the time period within 180 days after hospital discharge after aortic valve therapy with SAVR or TAVI, and longer follow-up periods might be necessary to address other consequences of delirium in this patient group.

\section{INTRODUCTION}

Surgical aortic valve replacement (SAVR) and transcatheter aortic valve implantation (TAVI) have resulted in successful outcomes, even in very old patients. ${ }^{1-4}$ An increasing number of older cardiovascular patients expect improvements in physical function and independence, without compromising longevity. ${ }^{5}{ }^{6}$ However, there are trade-offs in performing surgery in older patients that works against these goals. The effect delirium has on short-term and long-term morbidity and mortality in octogenarian patients undergoing SAVR or TAVI is of interest to clinicians who refer and treat these patients, and also to healthcare providers aiming to improve quality of hospital care. ${ }^{7}$ 
Delirium is an acute and fluctuating change in attention and cognition that increases the risk for functional decline, institutionalisation and death in hospitalised older patients. ${ }^{8}$ The incidence of delirium in octogenarians after aortic valve therapy can be as high as $56 \% .^{9}$ Yet, it is less likely to occur in patients undergoing the less invasive TAVI than in those receiving SAVR, ${ }^{9}$ even though TAVI patients are usually older, have more advanced left ventricular dysfunction and often have several comorbidities. ${ }^{2}$

The relationship between delirium, cardiac surgery and undesirable events such as hospital readmissions and mortality has previously been studied. ${ }^{10}{ }^{11}$ However, to the best of our knowledge, the role that delirium plays in these outcomes in the oldest group of patients after receiving SAVR or TAVI remains to be established. Little is known also about the causes of short-term and long-term readmissions in this patient cohort. Therefore, the aim of this study was to (1) determine whether the presence of postoperative delirium can predict the risk of first-time readmissions and mortality in octogenarian patients within 180 days after SAVR or TAVI, and (2) to identify causes of these first-time readmissions (ie, discharge diagnoses) in patients who had delirium. We hypothesised that delirium leads to higher rates of readmission and mortality.

\section{METHODS}

\section{Design and setting}

We conducted a prospective cohort study of consecutively admitted octogenarian patients treated for severe aortic stenosis (AS) with SAVR or TAVI. The study was performed in a tertiary university hospital in Norway. This hospital is responsible for performing SAVR and TAVI procedures for the entire western region of Norway, which comprises more than 1300000 inhabitants. ${ }^{12}$ Follow-up was performed 30 and 180 days after hospital discharge.

\section{Study population}

Participants were recruited into the larger 'Delirium in octogenarians undergoing cardiac surgery or intervention (CARDELIR)' study. ${ }^{9}$ Inclusion criteria were age of 80 years or older and previous acceptance for elective AS treatment with SAVR or TAVI. Exclusion criteria were patients' declined consent to join the study or inability to speak Norwegian. The primary end point of CARDELIR was the presence of postoperative delirium.

Prior to inclusion, a heart team, consisting of cardiothoracic surgeons and invasive cardiologists, assessed the severity of $\mathrm{AS}^{13}$ and identified patients ineligible for SAVR. Reasons for disqualifying patients for traditional aortic valve replacements were previous coronary artery bypass graft, severe respiratory insufficiency, comorbidities that could compromise recovery and prior thoracic radiotherapy. Between February 2011 and August 2013, 162 octogenarians received elective AS treatment. Of these, 15 did not fulfil the inclusion criteria, and 3 patients failed to be identified prior to treatment due to administrative reasons. A total of 144 patients agreed to participate. The data of 136 of these are presented in this study. One of the 144 withdrew consent prior to treatment, and for 7 patients delirium could not be assessed, because they were non-responsive after surgery or had died (figure 1). TAVI was performed in 63 patients $(46 \%)$. Patients were classified as delirious if delirium was objectively identified on at least 1 of the 5 postoperative days. Some patients were not assessed for the presence of delirium on each day due to administrative or other reasons not related to the study, and thus were classified according to their delirium status for the days they were assessed. ${ }^{14}$

\section{MEASUREMENTS \\ Delirium}

The presence of delirium was established with the confusion assessment method (CAM) ${ }^{15}$ CAM is based on nine operationalised criteria from the Diagnostic and Statistical Manual of Mental Disorders (DSM-IV), and four

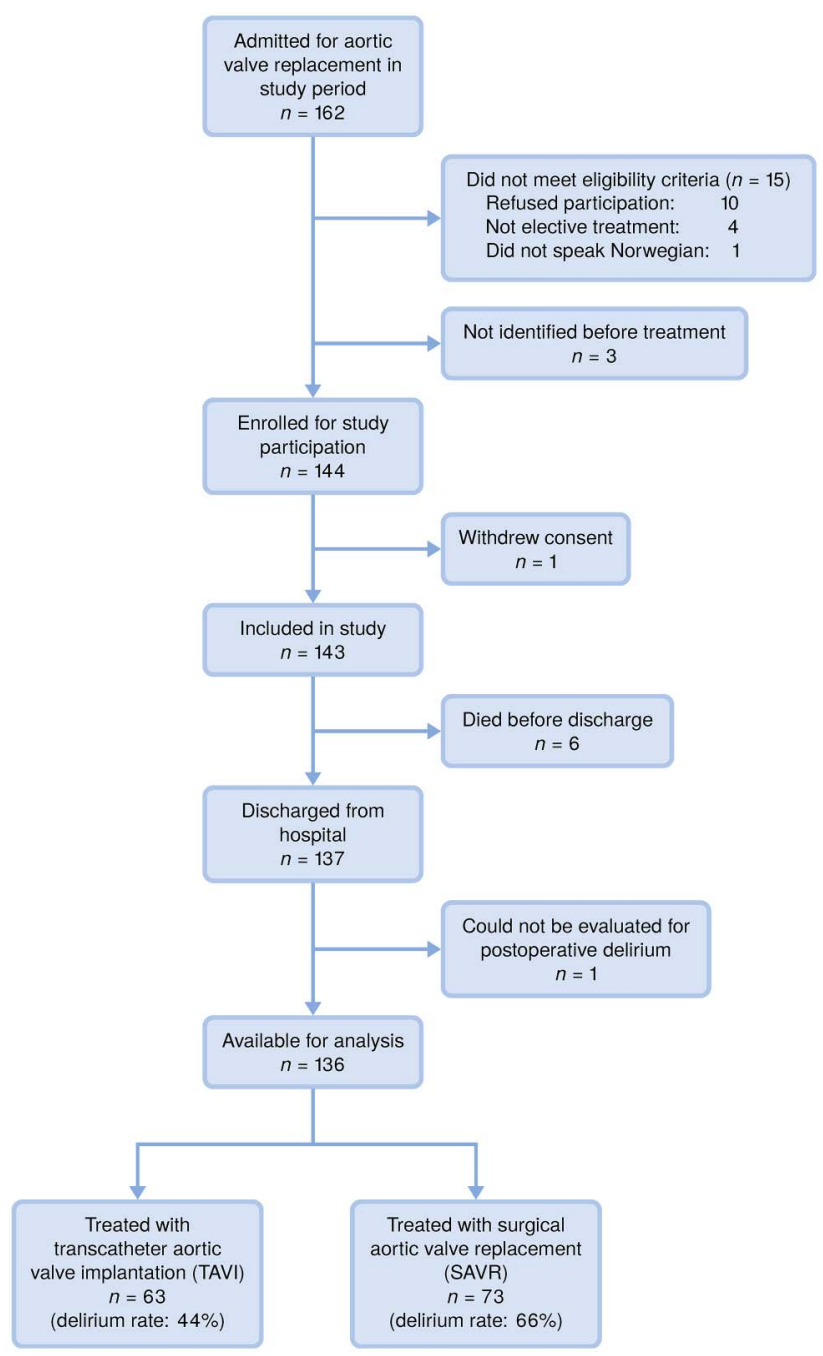

Figure 1 Flow chart of included patients. 
features: (1) acute onset and fluctuating course, (2) inattention, (3) disorganised thinking and (4) altered level of consciousness. Delirium is diagnosed when features 1 and 2 are present, and either 3 or 4 are displayed. CAM is a valid and reliable instrument. ${ }^{16}$

\section{Patients' general characteristics, health and comorbidities}

The Mini-Mental State Examination (MMSE) was used to assess general preoperative cognitive function. ${ }^{17}$ The MMSE uses an assessment scale from 0 to 30 , in which low scores represent lower levels of functioning. ${ }^{17} 18$

The Barthel index ${ }^{19}$ was used to assess patients' basic self-care abilities. The total score on the scale ranges from 0 to 20, with high scores indicating higher levels of independence. $^{19-21}$

We used the Nottingham Extended Activities of Daily Living Scale (ADL) to evaluate the patients' ability to perform tasks reflecting complex levels of functioning. ${ }^{22}$ The highest score on the scale is 66 , representing a high level of independence. ${ }^{22} 23$

We established the burden of comorbidity with the Charlson comorbidity index (CCI). This instrument predicts 10 -year mortality by assigning values to different comorbid conditions. ${ }^{24} 25$

Cardiac operative risk was evaluated with the Logistic European System for Cardiac Operative Risk Evaluation I (Logistic EuroSCORE I) ${ }^{26}$ The logistic EuroSCORE I predicts operative mortality using 17 risk variables, and high scores reflect a higher risk for mortality. ${ }^{27}$

\section{Data collection}

\section{Baseline data and postoperative assessment of delirium}

A description of data collection at baseline and the assessment of postoperative delirium were presented previously. ${ }^{9}$ Briefly, patients fulfilling the inclusion criteria were identified and approached the day before surgery. The study was explained and participants gave informed consent to enrolment before data collection started. Delirium was assessed by the first author and by members of the research team trained in the use of CAM. These members have their clinical practice at the Department of Heart Disease and they participated in information meetings regarding delirium given to healthcare providers in our department. They also received one-on-one sessions that covered more extensive knowledge regarding delirium, that included several examples about its features and that explained the use of CAM. Assessment of delirium was performed daily, at noon, from postoperative day 1 to day 5 , including weekends. Medical, nursing and physiotherapists' reports from the previous 24 hours were also considered when CAM was scored.

\section{Follow-up at 30 and 180 days}

The hospital information registry provided information required to identify first-time readmission and discharge diagnoses in accordance with the International Statistical Classification of Diseases and Related Health Problems, 10th
Revision (ICD-10).$^{28}$ The registry also helped to identify time of death for deceased patients who had been assessed for delirium earlier.

\section{Study outcomes}

The primary outcome was a composite variable of time from discharge to first all-cause readmission or death, from hospital discharge to 30 and 180 days after discharge. Secondary outcomes were all-cause first readmission alone and mortality 30 and 180 days after discharge, and the primary diagnosis at discharge from first-time readmission.

\section{Other study variables}

Gender, age, baseline MMSE scores and comorbidity (CCI), as well as type of therapy (SAVR and TAVI) as confounders, were selected based on guidance from previous literature ${ }^{29} 30$ and clinical experience.

\section{Statistical analysis}

Data are presented as counts and percentages, or means and SDs. Differences between groups at baseline were tested with the $\chi^{2}$ test for categorical variables and the t-test for continuous variables. The Kaplan-Meier survival curves and an exact Gehan-Breslow test stratified by type of aortic valve therapy were used to examine and test for differences in time to readmission/death. The Gehan-Breslow test was chosen because it places greater weight on early events. The exact conditional distribution of the test statistic was evaluated using a Monte Carlo procedure with 100000 replications, using the R package 'coin' ${ }^{31}$ V.1.1-2. The Cox proportional hazard regression analyses stratified by therapy type (SAVR/ TAVI) were used to adjust for gender, age (as a nonlinear/quadratic effect), MMSE and comorbidities. Statistical analyses were performed using IBM SPSS for Windows, V.22.0 (IBM SPSS Statistics for Windows [program]. 22.0 version. Armonk, NY: IBM Corp, 2013) and R V.3.2.3 (R Foundation for Statistical Computing, Vienna, Austria) (R Core Team. R: a language and environment for statistical computing. Secondary R: a language and environment for statistical computing. 2015. https://www.R-project.org/). A two-tailed p value of $\leq 0.05$ was considered statistically significant.

\section{Ethical considerations}

Research involving older patients requires special consideration with respect to functional disabilities and complex health conditions. Therefore, data collection was performed by members of the research team with extensive experience with geriatric and cardiac patients. Special attention was paid to signs of distress or fatigue, and data collection was stopped when such signs were present.

In order to guarantee confidentiality, independent access to information regarding first-time readmission from each of the five referring hospitals the patients belonged to had to be obtained. 


\section{Patient involvement}

No patients were involved in the design and implementation of the study. However, patient self-report is at the very core of the CARDELIR study. ${ }^{9} 1432{ }^{33}$ Also, 10 patients participated in qualitative interviews to describe their experiences with delirium. ${ }^{34}$ There are plans to disseminate the results of the research to the patient community through patient organisations.

\section{RESULTS}

\section{Baseline characteristics and postoperative delirium}

Table 1 shows the overall baseline characteristics of included patients $(n=136)$. Table 2 presents characteristics of patients assessed for delirium, according to readmissions or death 30 and 180 days after discharge from SAVR or TAVI. Compared with patients treated with SAVR, octogenarian patients undergoing TAVI were older (82.3 vs 84.8 years, $\mathrm{p}<0.001$ ); had lower MMSE scores (26.5 vs 27.8, $\mathrm{p}=0.009)$; greater number of comorbidities (2.4 vs 1.8, p=0.001); higher logistic EuroSCORE (19.6 vs $9.4, \mathrm{p}<0.001)$ and more often had American Society of Anesthesiologist physical status classification system (ASA) scores of IV (21 vs $2, \mathrm{p}<0.001)$. No differences in gender $(63 \%$ female vs $51 \%$ male, $\mathrm{p}=0.11)$ or in the performance of ADL (18.8 vs 19.0, $\mathrm{p}=0.31$ ) were found between the SAVR and TAVI groups. Of the 136 patients assessed, 56\% developed delirium. Delirium was identified in $44 \%$ of patients treated with

\begin{tabular}{|c|c|c|}
\hline Variables & Count/mean & $\begin{array}{l} \pm \mathrm{SD} \\
\text { or }(\%\end{array}$ \\
\hline Age (years) & 83.5 & \pm 2.7 \\
\hline Women & 76 & (56) \\
\hline Married & 73 & (54) \\
\hline MMSE & 27.2 & \pm 2.9 \\
\hline Barthel index & 18.9 & \pm 1.4 \\
\hline Nottingham IADL & 54.2 & \pm 10.1 \\
\hline BMI $\left(\mathrm{kg} / \mathrm{m}^{2}\right)$ & 25.5 & \pm 4.2 \\
\hline Charlson comorbidity index & 2.1 & \pm 1.2 \\
\hline Logistic EuroScore & 14.0 & (9.2) \\
\hline NYHA function class I+II & 47 & (35) \\
\hline NYHA function class III+IV & 75 & (55) \\
\hline Left ventricle ejection fraction (\%) & 56.6 & \pm 10.2 \\
\hline Max aorta gradient $(\mathrm{mm} \mathrm{Hg})$ & 79.5 & \pm 23.9 \\
\hline Mean aorta gradient $(\mathrm{mm} \mathrm{Hg})$ & 48.3 & \pm 16.1 \\
\hline Aortic valve area $\left(\mathrm{cm}^{2} / \mathrm{m}^{2}\right)$ & 0.4 & \pm 0.2 \\
\hline Preoperative atrial fibrillation & 39 & (27) \\
\hline ASA classification III & 114 & (84) \\
\hline ASA classification IV & 22 & (16) \\
\hline Treatment: TAVI & 65 & (45) \\
\hline Delirium (yes) & 76 & (56) \\
\hline
\end{tabular}

ASA, American Society of Anesthesiologist physical status classification system; BMI, body mass index; IADL, instrumental activities of daily living; MMSE, Mini-Mental State Examination; NYHA, New York Heart Association Functional Classification; TAVI, transcatheter aortic valve implantation.
TAVI and in $66 \%$ of those receiving SAVR $(p=0.01)$. The average number of days with delirium for patients treated with SAVR was 1.5 days and for patients treated with TAVI, 1.1 days $(\mathrm{p}=0.20)$. A table showing living environment within 30 and 180 days after open surgery or transcatheter intervention is presented in online supplementary appendix 1 .

\section{Readmissions and mortality}

Figure 2 presents the proportions of types of discharge diagnoses following first-time readmission, 30 and 180 days after therapy with SAVR or TAVI, according to the ICD-10, and stratified by the presence/absence of delirium.

\section{Readmissions and mortality within $\mathbf{3 0}$ days after discharge}

Of the 30 patients $(22 \%)$ readmitted for the first time within 30 days after SAVR or TAVI, $24(80 \%)$ had delirium. The majority of readmitted patients in the delirium group returned to the hospital for cardiovascular disorders with no dominant-specific diagnoses, and only two patients returned because of heart failure. Eight per cent of the readmitted patients in the delirium group exhibited symptoms such as chest pain and dyspnoea, and had contact with health services, whereas $4 \%$ of the readmitted patients were hospitalised for external injuries such as fall injuries.

Cardiovascular disorders were causes of first-time readmission in two of the non-delirious patients and another two were readmitted due to pneumonia. One patient in the non-delirious group died within 30 days after discharge.

\section{Readmissions and mortality within $\mathbf{1 8 0}$ days of discharge}

Of the 58 patients readmitted for the first-time within 180 days after aortic valve therapy, $37(64 \%)$ were in the group that had delirium. Readmission diagnoses for patients who had delirium covered a wide variety of ICD-10 categories, with diagnoses related to the circulatory system being the most common (13\%). Heart failure was identified in $4 \%$ of first-time readmissions, and complications after cardiac surgery in $3 \%$. Additional readmissions were related to pulmonary hypertension and embolism, other heart diseases and myocardial infarction. Fall injuries or other complications resulted in $5 \%$ of first-time readmissions.

In patients without delirium, diseases of the circulatory system were responsible for $15 \%$ of first-time readmissions. Heart failure and arrhythmias were the most common. Three patients $(5 \%)$ were readmitted because of injuries like bone fractures, and three had pneumonia. Six out of eight patients who died within 180 days after aortic valve therapy had postoperative delirium.

\section{Survival analyses}

Figure 3 shows survival curves for 30-day and 180-day readmissions and mortality according to delirium and type of aortic valve therapy. After stratifying for type of 
Table 2 Characteristics of patients assessed for delirium, according to readmissions or death 30 and 180 days after discharge from surgical aortic valve replacement or transcatheter aortic valve implantation $(n=136)$

\begin{tabular}{|c|c|c|c|c|c|c|c|c|c|c|}
\hline \multirow[b]{3}{*}{ Variables } & \multicolumn{5}{|l|}{30 days } & \multicolumn{5}{|l|}{180 days } \\
\hline & \multicolumn{2}{|c|}{ Non-readmitted } & \multicolumn{2}{|c|}{$\begin{array}{l}\text { Readmitted or } \\
\text { dead }\end{array}$} & \multirow[b]{2}{*}{$\begin{array}{l}p \\
\text { Value }\end{array}$} & \multicolumn{2}{|c|}{ Non-readmitted } & \multicolumn{2}{|c|}{$\begin{array}{l}\text { Readmitted or } \\
\text { dead }\end{array}$} & \multirow[b]{2}{*}{$\begin{array}{l}p \\
\text { Value }\end{array}$} \\
\hline & $\begin{array}{l}\text { Mean or } \\
\text { count }\end{array}$ & $\begin{array}{l} \pm \text { SD or } \\
(\%)\end{array}$ & $\begin{array}{l}\text { Mean or } \\
\text { count }\end{array}$ & $\begin{array}{l} \pm \text { SD or } \\
(\%)\end{array}$ & & $\begin{array}{l}\text { Mean or } \\
\text { count }\end{array}$ & $\begin{array}{l} \pm \text { SD or } \\
(\%)\end{array}$ & $\begin{array}{l}\text { Mean or } \\
\text { count }\end{array}$ & $\begin{array}{l} \pm \text { SD or } \\
(\%)\end{array}$ & \\
\hline Age (years) & 83.3 & 2.7 & 83.9 & 2.6 & 0.29 & 83.5 & 2.7 & 83.3 & 2.6 & 0.66 \\
\hline Women & 62 & (59) & 14 & (45) & 0.17 & 46 & (59) & 30 & (52) & 0.40 \\
\hline Married & 55 & (52) & 18 & (58) & 0.58 & 43 & (55) & 30 & (52) & 0.69 \\
\hline MMSE & 27.1 & 3.0 & 27.5 & 2.8 & 0.49 & 27.2 & 3.1 & 27.3 & 2.7 & 0.74 \\
\hline Barthel index & 19.1 & 1.3 & 18.4 & 1.8 & 0.05 & 19.3 & 1.1 & 18.5 & 1.7 & 0.002 \\
\hline Nottingham IADL & 54.7 & 9.5 & 52.7 & 11.9 & 0.44 & 56 & 9.3 & 51.7 & 10.8 & 0.03 \\
\hline $\mathrm{BMI}\left(\mathrm{kg} / \mathrm{m}^{2}\right)$ & 25.4 & 4.4 & 25.7 & 3.5 & 0.68 & 25.7 & 4.4 & 25.2 & 3.9 & 0.44 \\
\hline $\begin{array}{l}\text { Charlson comorbidity } \\
\text { index }\end{array}$ & 2.03 & 1.1 & 2.3 & 1.2 & 0.25 & 1.9 & 1.1 & 2.3 & 1.2 & 0.09 \\
\hline Logistic EuroScore & 13.4 & 8.1 & 16.1 & 12 & 0.24 & 13.1 & 8.3 & 15.1 & 10.3 & 0.24 \\
\hline NYHA function class & & & & & 0.28 & & & & & 0.02 \\
\hline$I+I I$ & 39 & (41) & 8 & (30) & & 33 & (47) & 14 & (27) & \\
\hline III+IV & 56 & (59) & 19 & (70) & & 37 & (53) & 38 & (73) & \\
\hline LVEF (\%) & 57.7 & 9.6 & 52.8 & 11.5 & 0.04 & 57.9 & 9.6 & 54.7 & 10.8 & 0.07 \\
\hline $\begin{array}{l}\text { Maximum aorta } \\
\text { gradient }(\mathrm{mm} \mathrm{Hg})\end{array}$ & 80.6 & 24.7 & 75.5 & 20.6 & 0.27 & 78.3 & 22.8 & 81.1 & 25.5 & 0.51 \\
\hline $\begin{array}{l}\text { Mean aorta gradient } \\
(\mathrm{mm} \mathrm{Hg})\end{array}$ & 49.3 & 16.7 & 45 & 13.6 & 0.15 & 47.7 & 15.5 & 48.9 & 16.9 & 0.7 \\
\hline $\begin{array}{l}\text { Aortic valve area } \\
\left(\mathrm{cm}^{2} / \mathrm{m}^{2}\right)\end{array}$ & 0.38 & 0.11 & 0.44 & 0.28 & 0.3 & 0.4 & 0.11 & 0.40 & 0.22 & 0.9 \\
\hline ASA classification & & & & & 0.27 & & & & & 0.22 \\
\hline III & 90 & (86) & 24 & (77) & & 68 & (87) & 46 & (79) & \\
\hline IV & 15 & (14) & 7 & (23) & & 10 & (13) & 12 & (21) & \\
\hline Treatment: TAVI & 50 & (48) & 13 & (42) & 0.58 & 35 & (45) & 28 & (48) & 0.69 \\
\hline
\end{tabular}

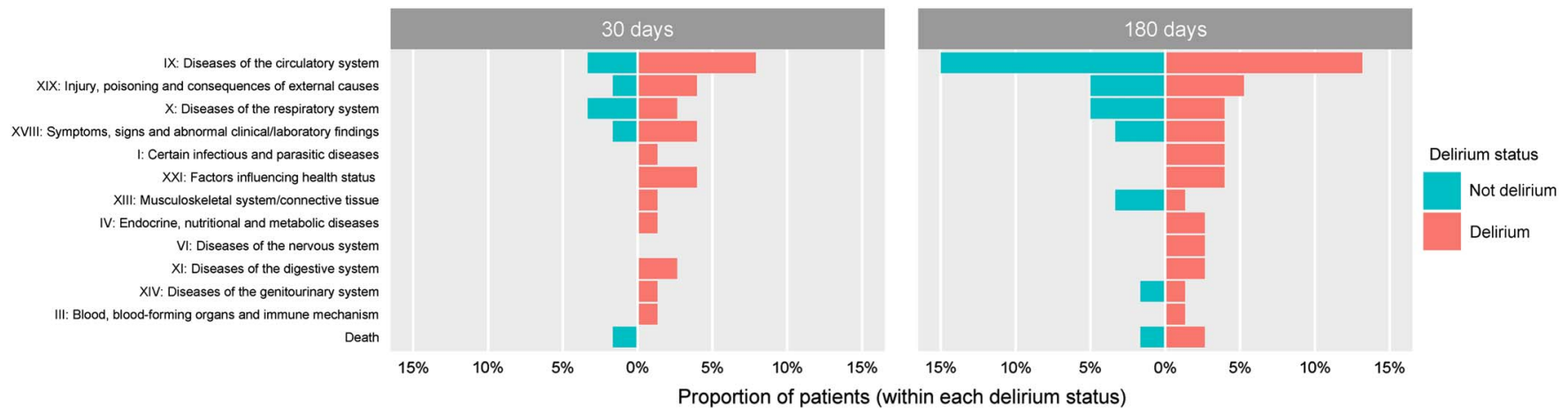

Figure 2 Proportions of discharge diagnoses or death following first readmission/death within 30 or 180 days after initial discharge, according to the presence of delirium and in accordance with the International Statistical Classification of Diseases and Related Health Problems, 10th Revision (ICD-10).

therapy (SAVR vs TAVI), differences were revealed in time to readmission and mortality between patients with and without delirium within 180 days after discharge $(p=0.02)$. These differences were already present 30 days after discharge $(\mathrm{p}=0.006)$.

Initial analyses revealed that the effect of delirium was not well described by the Cox proportional hazard model ( $p=0.03$ in a test for the proportional hazard assumption). Examination of Schoenfeld residuals indicated that the effect of delirium on hazard diminished over time, and this was particularly pronounced starting about 60 days after initial discharge. We therefore fitted a model using a factor for a time-dependent effect of delirium, in which the effect was constant up to 60 days (ie, assuming proportional hazards up to this time point) and then linear with time from 60 to 180 days 
Figure 3 Kaplan-Meier survival curves for first-time readmission or death, stratified by postoperative delirium and treatment procedure with surgical aortic valve replacement (SAVR) or transcatheter aortic valve implantation (TAVI).

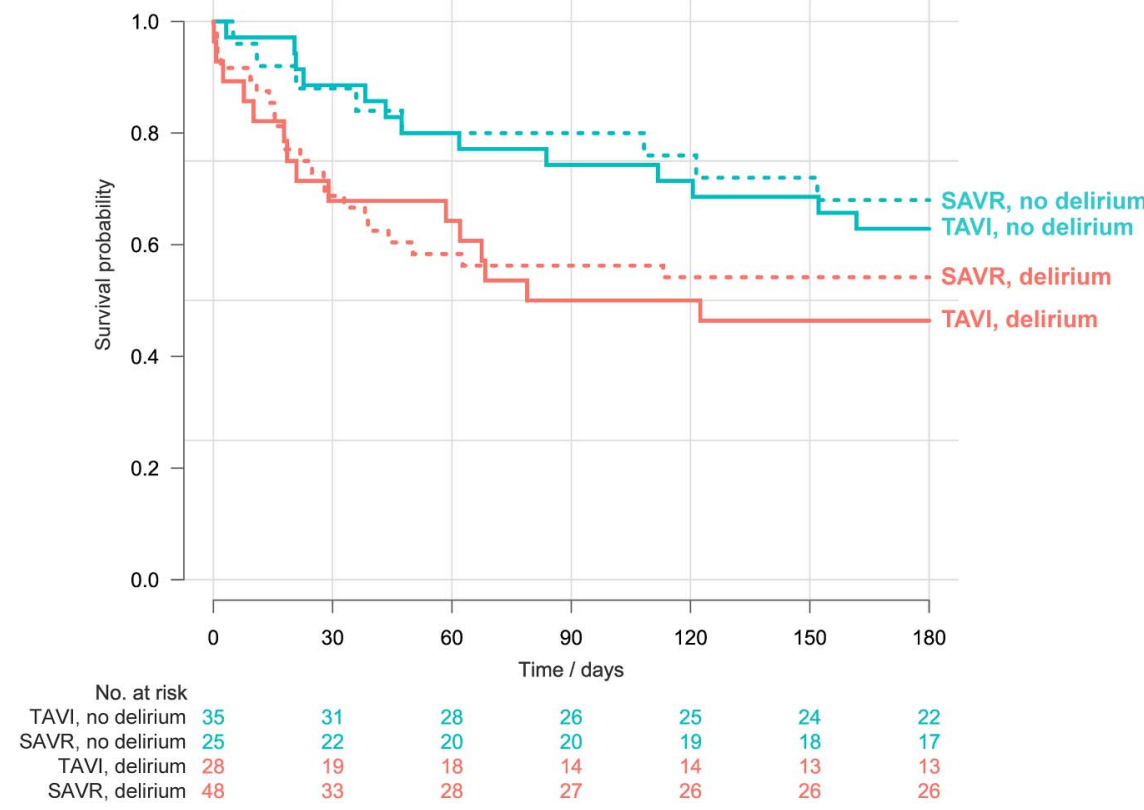

(table 3). This greatly improved the model fit, and a test of model assumptions no longer indicated any lack of fit. The HR up to 60 days was estimated to be $2.9(95 \%$ CI 1.5 to 5.7). The effect was reduced over time (an estimated reduction of about $3 \%$ for each day after the 60 th day), but there is great uncertainty in these estimates, due to a low number of later events. For example, there were only six events between 120 and 180 days, making it impossible to obtain reliable estimates for the shape of the time-dependent HR for this period. Additional completely stratified analyses did not find any effect modification (results not reported).

\section{DISCUSSION}

This prospective study shows that delirium is a serious postoperative complication that predicts first-time readmissions and death in octogenarian patients who have had SAVR or TAVI therapy. The number of first-time readmissions or deaths within 180 days after SAVR or TAVI was considerably higher for patients who experienced delirium, and this difference was especially pronounced within 30 days after therapy. The most common cause of first-time readmission in all included patients was related to heart failure; injuries and infections also were frequent diagnoses. In octogenarians who experienced delirium, reasons for first-time readmission covered all general diagnostic categories of the ICD-10, and included symptoms lacking specific pathology and contact with health services without a specific diagnosis. In the group not experiencing delirium, first-time readmissions were most often related to disorders of the circulatory system. Mortality was higher in the group of patients who experienced delirium.

Despite originating from a single centre, this study includes data on the entire western region of Norway, which has a population of more than $1300000^{35}$ and covers the total population of five other regional hospitals. Health services in Norway provide equal access to free hospital treatment, medication and hospital accommodation to everyone who is part of the National Insurance Scheme. Advanced treatments, such as SAVR and TAVI, are performed only in specialised hospitals like ours. The high rate of inclusion in this study ensures that the data are representative of octogenarians with severe AS referred for SAVR or TAVI in Norway and in other industrialised countries with a similar health system. This makes our results comparable to other

Table 3 Cox regression model (with time-dependent effect of delirium) for time to first readmission/death within 180 days after initial discharge from hospital $(n=136)$

\begin{tabular}{llll}
\hline & HR & $\mathbf{9 5 \%} \mathbf{C l}$ & $\mathbf{p ~ V a l u e ~}$ \\
\hline Treatment* & - & - & - \\
Gender (female) & 0.76 & 0.44 to 1.31 & 0.33 \\
Age (linear and non-linear effects) & - & - & 0.99 \\
Charlson comorbidity index & 1.25 & 1.00 to 1.57 & 0.06 \\
MMSE & 1.03 & 0.94 to 1.13 & 0.48 \\
Delirium & 2.93 & 1.51 to 5.67 & 0.002 \\
Delirium $\times($ no. of days after 60) & 0.97 & 0.94 to 0.99 & 0.02 \\
\hline${ }^{*}$ Treatment (TAVI vs SAVR) was included as a stratification variable. & &
\end{tabular}


studies that sampled from more populated areas. ${ }^{29} 30$ Octogenarian patients are increasingly being recipients of advanced treatments such as SAVR and TAVI, and our results may also be applied in other settings where advanced treatment is offered to the elderly.

Previous research has provided important information regarding the survival of patients treated with SAVR or TAVI. ${ }^{36-38}$ The primary outcome of these studies was survival $1,{ }^{38} 2^{36}$ and 5 years ${ }^{37}$ after the procedure. However, older patients seeking this therapy expect that it will not only increase their longevity, but also will reduce disability and help them avoid further hospitalisations. ${ }^{39}$ These expectations are at variance with our previous findings. We showed that patients treated with TAVI and who had postoperative delirium experienced significant decreases in ADL and IADL functions 1-month after therapy. ${ }^{14}$ A recent study also showed an association between physical impairment and 30 days all-cause hospital readmission. ${ }^{40}$ Moreover, in the present study, patients with delirium had a much higher rate of all-cause readmissions and death 30 days after discharge than those without delirium, regardless of the type of AS therapy. These results may suggest that patients at risk for developing delirium are more vulnerable at baseline and continue to be vulnerable at hospital discharge, hence explaining the higher risk for later hospitalisations and death. This highlights the effect that delirium may have in this patient group.

Our results can be compared with those of a previous study on 30-day readmissions among patients treated with SAVR or TAVI. ${ }^{30}$ This study did not find significant differences in 30-day readmissions between therapy types. However, the study differed from ours in that it focused on readmissions as a function of therapy type only, and did not take delirium status into consideration. A recently published study examining 1-year mortality in SAVR and TAVI patients according to the presence or absence of delirium found a positive association between the presence of delirium and morbidity and mortality, ${ }^{41}$ a finding that is consistent with our results. However, their study differed in that its assessment was limited to the initial stay in the intensive care unit, used a retrospective design and did not assess readmissions and mortality within the first 6 months after discharge.

Our study provides important new evidence showing that postoperative delirium is an undesirable outcome in older patients, especially octogenarians, undergoing treatment for AS. A previous study found a lower incidence of delirium after TAVI compared with SAVR. ${ }^{9}$ However, the short-term and long-term consequences of delirium for TAVI patients emphasise the need to implement strategies early on to reduce its development and also to possibly develop a specific TAVI risk score. ${ }^{42}$ Strong evidence supports multicomponent interventions to prevent delirium in hospitalised patients, ${ }^{43}$ and our results suggest that such interventions should be implemented in hospital settings where SAVR and TAVI are offered, especially since these procedures are often performed on older people. Knowledge about how delirium affects first-time readmissions and mortality following aortic valve therapy might facilitate clinical decision-making and dialogue between patients and physicians when deciding a treatment path. Better clinical tools to predict which patients are at risk to develop postoperative delirium are also warranted, as these tools would identify at-risk patients who should receive either medical treatment or undergo the least invasive surgical modality.

There are several strengths to our study, including its prospective design and the use of a valid and reliable instrument to assess delirium for 5 postoperative days. The tertiary university hospital in which data were collected and the low number of patients who refused participation $(6 \%)$ provides the possibility of generalisation not only in terms of the western part of Norway, but also to other western populations where SAVR and TAVI are offered to octogenarian patients. An additional strength is found in the fact that patient's readmissions were completely blinded for the research team.

The lack of randomisation is a limitation. However, since SAVR and TAVI were offered different treatment groups with regard to surgical risk factors, a randomised design was not possible. ${ }^{2}$ The modest sample size has also limited the possibility of more analyses. Another limitation of our study lies in the lack of inter-rater reliability measurement. Even though the majority of assessments for delirium were performed by the first author, there were cases (ie, some weekends and holydays) where other members of the research team were responsible for using the CAM.

It remains to be established whether delirium is causally related to the higher number of readmissions and deaths 30 and 180 days after discharge, or whether patients with several readmissions are already more vulnerable before aortic valve therapy, and therefore more prone to develop delirium. Future research should address the consequences of delirium in this patient group using a longer follow-up period.

\section{CONCLUSIONS}

First-time hospital readmissions and mortality within 30 and 180 days after hospital discharge were more often present in octogenarian patients who had postoperative delirium after SAVR or TAVI therapy. Our results suggest that delirium may be a serious risk factor for negative events leading to readmissions and death in octogenarian patients treated with SAVR for severe AS, and even for those treated with the less invasive TAVI therapy.

Author affiliations

${ }^{1}$ Faculty of Health and Social Sciences, Bergen University College, Bergen, Norway

${ }^{2}$ Department of Clinical Science, University of Bergen, Bergen, Norway ${ }^{3}$ School of Health and Welfare, Jönköping University, Jönköping, Sweden ${ }^{4}$ Department of Heart Disease, Haukeland University Hospital, Bergen, Norway ${ }^{5}$ Centre for Clinical Research, Haukeland University Hospital, Bergen, Norway

${ }^{6}$ Department of Cardiology, Stavanger University Hospital, Stavanger, Norway 
Contributors LSPE, AHR, JEN and TMN are responsible for study concept and design. LSPE and TMN are responsible for data collection. KOH, LSPE, AHR and TMN are responsible for analysis of data. LSPE, AHR, KOH, BF, RH, KKJK, JEN and TMN are responsible for interpretation of data. LSPE, AHR, BF and TMN are responsible for initial draft of manuscript. All authors revised the paper critically for important intellectual content and approved the final version of the manuscript. LSPE, TMN and KOH had full access to all of the data (including statistical reports and tables) in the study and take responsibility for the integrity of the data and the accuracy of the data analysis.

Funding This work was supported by a full research grant from the University of Bergen to LSPE. The study also received funding from Bergen University College, the Norwegian Nurses Association and Kavli Research Center for Geriatrics and Dementia.

Patient consent Obtained.

Ethics approval CARDELIR was approved by the Regional Committee for Ethics in Medical Research (REK Vest 2010/2936-6) and conducted in accordance with the Declaration of Helsinki.

Provenance and peer review Not commissioned; externally peer reviewed.

Data sharing statement No additional data are available.

Open Access This is an Open Access article distributed in accordance with the Creative Commons Attribution Non Commercial (CC BY-NC 4.0) license, which permits others to distribute, remix, adapt, build upon this work noncommercially, and license their derivative works on different terms, provided the original work is properly cited and the use is non-commercial. See: http:// creativecommons.org/licenses/by-nc/4.0/

\section{REFERENCES}

1. Bekeredjian R, Krumsdorf U, Chorianopoulos E, et al. Usefulness of percutaneous aortic valve implantation to improve quality of life in patients $>80$ years of age. Am J Cardiol 2010;106:1777-81.

2. Leon MB, Smith CR, Mack M, et al. Transcatheter aortic-valve implantation for aortic stenosis in patients who cannot undergo surgery. N Engl J Med 2010;363:1597-607.

3. Scandroglio AM, Finco G, Pieri M, et al. Cardiac surgery in 260 octogenarians: a case series. BMC Anesthesiol 2015;15:15.

4. Seco M, Edelman JJ, Forrest $P$, et al. Geriatric cardiac surgery: chronology vs. biology. Heart Lung Circ 2014;23:794-801.

5. Bell SP, Orr NM, Dodson JA, et al. What to expect from the evolving field of geriatric cardiology. J Am Coll Cardiol 2015;66:1286-99.

6. Forman DE, Rich MW, Alexander KP, et al. Cardiac care for older adults. Time for a new paradigm. J Am Coll Cardiol 2011;57:1801-10.

7. Inouye SK. Delirium: a barometer for quality of hospital care. Hosp Pract (1995) 2001;36:15-16. 18

8. Inouye SK, Westendorp RG, Saczynski JS. Delirium in elderly people. Lancet 2014;383:911-22.

9. Eide LS, Ranhoff $\mathrm{AH}$, Fridlund $\mathrm{B}$, et al. Comparison of frequency, risk factors, and time course of postoperative delirium in octogenarians after transcatheter aortic valve implantation versus surgical aortic valve replacement. Am J Cardiol 2015;115:802-9.

10. Mangusan RF, Hooper V, Denslow SA, et al. Outcomes associated with postoperative delirium after cardiac surgery. Am J Crit Care 2015;24:156-63.

11. Koster S, Hensens AG, Schuurmans MJ, et al. Consequences of delirium after cardiac operations. Ann Thorac Surg 2012;93:705-11.

12. Statistics Norway. Population projections, 2014-2100. Secondary Population projections, 2014-2100. 2014. https://www.ssb.no/en/ befolkning/statistikker/folkfram

13. Vahanian A, Alfieri $O$, Andreotti F, et al. Guidelines on the management of valvular heart disease (version 2012): the Joint Task Force on the Management of Valvular Heart Disease of the European Society of Cardiology (ESC) and the European Association for Cardio-Thoracic Surgery (EACTS). Eur J Cardiothorac Surg 2012;42:1-44.

14. Eide LS, Ranhoff $A H$, Fridlund $B$, et al. Delirium as a predictor of physical and cognitive function in octogenarians after transcatheter or surgical aortic valve replacement. J Am Geriatr Soc 2016;64:1178-86.

15. Inouye SK, van Dyck $\mathrm{CH}$, Alessi CA, et al. Clarifying confusion: the confusion assessment method. A new method for detection of delirium. Ann Intern Med 1990;113:941-8.
16. Wong CL, Holroyd-Leduc J, Simel DL, et al. Does this patient have delirium?: value of bedside instruments. JAMA 2010;304:779-86.

17. Folstein MF, Folstein SE, McHugh PR. 'Mini-mental state'. A practical method for grading the cognitive state of patients for the clinician. J Psychiatr Res 1975;12:189-98.

18. Foreman MD. Reliability and validity of mental status questionnaires in elderly hospitalized patients. Nurs Res 1987;36:216-20.

19. Mahoney FI, Barthel DW. Functional evaluation: the Barthel index. Md State Med J 1965;14:61-5.

20. Collin C, Wade DT, Davies S, et al. The Barthel ADL index: a reliability study. Int Disabil Stud 1988;10:61-3.

21. Sadaria KS, Bohannon RW, Lee N, et al. Ratings of physical function obtained by interview are legitimate for patients hospitalized after stroke. J Stroke Cerebrovasc Dis 2001;10:79-84.

22. Gladman JR, Lincoln NB, Adams SA. Use of the extended ADL scale with stroke patients. Age Ageing 1993;22:419-24.

23. Lincoln NB, Gladman JRF. The extended activities of daily living scale: a further validation. Disabil Rehabil 1992;14:41-3.

24. Charlson ME, Pompei P, Ales KL, et al. A new method of classifying prognostic comorbidity in longitudinal studies: development and validation. J Chronic Dis 1987;40:373-83.

25. Frenkel WJ, Jongerius EJ, Mandjes-van Uitert MJ, et al. Validation of the Charlson comorbidity index in acutely hospitalized elderly adults: a prospective cohort study. J Am Geriatr Soc 2014;62:342-6.

26. Roques F, Michel P, Goldstone AR, et al. The logistic EuroSCORE. Eur Heart J 2003;24:881-2.

27. EuroSCORE. Secondary EuroSCORE [Web Page]. 2003. http:// www.euroscore.org/index.htm

28. World Health Organization. International Classification of Diseases (ICD). Secondary International Classification of Diseases (ICD). 2016. http://apps.who.int/classifications/icd10/browse/2010/en

29. Gleason LJ, Schmitt EM, Kosar CM, et al. Effect of delirium and other major complications on outcomes after elective surgery in older adults. JAMA Surg 2015;150:1134-40.

30. Hannan EL, Samadashvili Z, Jordan D, et al. Thirty-day readmissions after transcatheter aortic valve implantation versus surgical aortic valve replacement in patients with severe aortic stenosis in New York State. Circ Cardiovasc Interv 2015;8:e002744.

31. Hothorn T, Hornik K, van de Wiel MA, et al. Implementing a class of permutation tests: the coin package. J Stat Software 2008;28:23.

32. Amofah HA, Broström A, Fridlund B, et al. Sleep in octogenarians during the postoperative phase after transcatheter or surgical aortic valve replacement. Eur J Cardiovasc Nurs 2016;15:168-77.

33. Olsen SJ, Fridlund B, Eide LS, et al. Changes in self-reported health and quality of life in octogenarian patients one month after transcatheter aortic valve implantation. Eur J Cardiovasc Nurs 2016. [Epub ahead of print 1 Apr 2016]

34. Instenes I, Gjengedal E, Eide LS, et al. A black mask covered his face... a death-mask. Experiences of delirium in octogenarians after aortic valve replacement. 5th Annual Meeting of the American Delirium Society; Baltimore, USA: Johns Hopkins University, 2015.

35. Statistics Norway. Population and population changes. Secondary Population and population changes. 2016. https://www.ssb.no/ statistikkbanken/selectvarval/saveselections.asp

36. Kodali SK, Williams MR, Smith CR, et al. Two-year outcomes after transcatheter or surgical aortic-valve replacement. $N$ Engl J Med 2012;366:1686-95.

37. Mack MJ, Leon MB, Smith CR, et al. 5-year outcomes of transcatheter aortic valve replacement or surgical aortic valve replacement for high surgical risk patients with aortic stenosis (PARTNER 1): a randomised controlled trial. Lancet 2015;385:2477-84

38. Smith CR, Leon MB, Mack MJ, et al. Transcatheter versus surgica aortic-valve replacement in high-risk patients. $N$ Engl J Med 2011;364:2187-98.

39. Bell SP, Patel N, Patel N, et al. Care of older adults. J Geriatr Cardiol 2016;13:1-7.

40. Greysen SR, Stijacic Cenzer I, Auerbach AD, et al. Functional impairment and hospital readmission in Medicare seniors. JAMA Intern Med 2015;175:559-65.

41. Maniar HS, Lindman BR, Escallier K, et al. Delirium after surgical and transcatheter aortic valve replacement is associated with increased mortality. J Thorac Cardiovasc Surg 2016;151:815-23. e1-2.

42. Auffret V, Boulmier D, Oger E, et al. Predictors of 6-month poor clinical outcomes after transcatheter aortic valve implantation. Arch Cardiovasc Dis 2014;107:10-20.

43. Siddiqi N, Harrison JK, Clegg A, et al. Interventions for preventing delirium in hospitalised non-ICU patients. Cochrane Database Syst Rev 2016;3:CD005563. 